\title{
Modeling Mexican Electricity Market: Experimental Results
}

Vitaly Kalashnikov, CIMAT, Guanajuato, Mexico

Nataliya Kalashnykova, University of Nuevo Leon, Mexico

Felipe de Jesús Castillo Pérez, University of Nuevo Leon, Mexico

\begin{abstract}
In this paper, we propose an oligopolistic model of electricity market of Mexico and analyze numerical experiments based upon this model. Presently, the Mexican electricity market is presented by the state-regulated monopoly, so a competition market is not yet established. Our work can be evaluated as an empirical study of possible liberalization effects for Mexico. An oligopolistic market structure emerges from the energy market analysis and is characterized not only by the mutual influence upon prices due to the market shares and power but also by the naturally limited number of operating firms-producers at the market. In this Cournot-Nash model, the electricity firms maximize their profit and enlarge their market shares. For a comparison, we also introduce the notion of perfect competition, where each agent reacts as a price-taker equalizing prices and marginal costs in order to maximize its profit. The computational game theoretic modeling tool, offered in this paper, composed as a mixed complementarity problem (MCP), solved by the GAMS (www.gams.com) algorithm PATH. It was applied to the Mexican electricity market data to obtain Nash equilibrium in the perfect competition and Cournot cases, as well as open market scenario with international trade with the USA.
\end{abstract}

Keywords: Cournot-Nash model, electricity market, mixed complementarity problem

\section{INTRODUCTION}

$\mathcal{G}$ lectricity systems are currently restructured, or about to be restructured, in many parts of the world. The process does not follow a single paradigm, but some features are common to most situations. Competition is introduced in generation of the electricity while transmission and distribution remain regulated monopolies. A new function, namely supply, is introduced, which matches loads and generation of different types. It is undertaken by generators and/or by intermediaries commonly referred to as "power marketers". Generators and/or power marketers need to have access to transmission and distribution services in order to reach their customers.

Thus, there also exists an organization in charge of supplying these services. A wide variety of institutions can be constructed on the basis of these few principles. Different paradigms of restructured electricity systems are already found in Europe and United States today.

To the liberalization process of the European energy market: guaranteed territorial monopolies were canceled in the electricity production, resulting in a new structure of energy supply and technologies. An industrial and household consumer has been granted free access to different electricity providers. In many cases we even get internal and external competition in the market due to foreign providers entering the market. The competition process of electricity markets provides for great changes and new challenges to all energy producers. Still, in order to provide a sufficient and long term cost efficient energy policy by the former "natural monopolies", as well as for an undistorted competition, strong guidelines from state authorities must be implemented.

Different kinds of non-cooperative games within various and spatially distinct markets have been examined by diverse authors. Murphy et al (1986) demonstrate mathematical programming approach in order to determine oligopolistic market equilibria. Salant and Shaffer (1999) illustrate the theoretical impacts on production and social 
welfare by two stage Cournot-Nash solutions by including investments due to learning by doing and R\&D determining marginal costs of identical agents differently.

On the road to perfect competition in the electricity market, strategic behavior (i.e., cooperation, refusal of collaboration, of refusal of net access) will determine the development of market structure of energy suppliers and the composition of technologies employed. Energy suppliers will optimize their production gains and their strategic behavior by maximizing market shares, increasing electricity prices, and lowering demand or consumption surplus. New energy products - such as energy services, and new market actors - such as electricity brokers, will be established. In particular, maximizing market shares could lead to higher electricity prices, increasing production and decreasing consumption surplus, while perfect competition warrants lower prices and market gains and an apparent increase of electricity demand.

The principal aim of the presented analysis was to investigate the different strategic behavior opportunities of Mexican market agent.

The paper is organized as follows. The next section contains a brief description of main ideas and links of the game theoretic modeling tool and describes the conjectural Nash equilibrium framework. The last section summarizes numerical test results and completes the paper with conclusions.

\section{GAME THEORETIC MODELING TOOL}

This section is based mainly on the paper by Kemfert and Kalashnikov (2002), which specified that the current Germany electricity market supply structure is characterized by natural oligopolies. Principal market agents are spatially separated in their current regional territories in Germany. Similarly, we allow the regional producers of the electricity, which now are belonging to Commission Federal de Electricidad (CFE), to act independently and offer their service not only to the regional, but also to neighboring regions customers. Electricity supply and demand by aggregated households and industry determine a regional equilibrium price. In order to investigate the effects of a liberalized electricity market in Europe/Germany, and we going to apply in now for Mexico, a computational analysis tool EMELIE was developed. It includes strategic behavior of firms and market agents.

EMELIE can be characterized as a computational game theoretic modeling tool in order to investigate strategic behavior by firms within the Europe. In this paper, we examine the case when, at the starting and the finishing stages of the game, electricity suppliers realize a Cournot-Nash equilibrium with their profits maximized. Profits are calculated upon marginal production costs and price dependent demand, the latter relationship being represented by an inverse demand function, which is twice continuously differentiable. At the intermediate stage of the game, firms maximize their profits given the strategic behavior of the other agents. Profits are computed on the base of variable production costs, maximum net power, net access costs and transportation costs.

Market shares, which may change with merges or cooperation, also play an important role. In the oligopolistic market structure, prices can be dependent upon the market shares and market powers. Prices are also influenced by the price elasticity of demand, and it is exactly here that the influence coefficients arise. In a situation of perfect competition, which we calculate for a comparison reason, that is not the case.

\section{PROBLEM SPECIFICATION}

When solving optimization problems, it is often useful to remember that each such a problem can be reduced to a complementarity problem. Generally speaking, in the complementarity framework, either a nonnegative variable is zero or the corresponding inequality constraint is active, i.e. is in fact an equality. Primarily, by solving a mixed complementarity problem (MCP), the Karush-Kuhn-Tucker (KKT) optimality conditions are determined and solved for a decision variable. The MCP format and the KKT conditions are equivalent. Therefore, each MCP can be transformed to the classical optimality conditions and vice versa. The idea behind the MCP formulation is to develop a program that permits the classical decomposition method to be obsolete, instead ascertaining the MCP conditions directly. The main advantages of MCP are: (1) the simultaneous and parallel determination of decision variables and side constraints, and (2) the solution of complex mathematical programs without an explicit 
formulation of the objective function. Specially developed solvers detect the MCP format directly and point out, if necessary, if side constraints are defined incorrectly. Present day computer technologies allow an uncomplicated and fast solution of MCPs by mathematical algorithms. At this moment, for instance, GAMS provides MILES and PATH as major solvers. In addition, applying the MCP method one avoids the intricacy of finding a solution by a standard nonlinear programming (NLP) solver when the starting values are distant from the optimum point.

Transforming an optimization problem into a MCP formulation requires a specification of the first order optimality conditions taking into account all upper and lower bounds of the decision variables. The MCP format allows a quite simple characterization of simultaneously processed decision variables (as in Games Theory) and a fast solution procedure. GAMS provides this highly efficient formulation mainly to realize reciprocal modeling approaches arising, for example, in game theoretic or applied general equilibrium concepts, $c f$. Ferris and Pang (1995).

\section{CONJECTURAL COURNOT-NASH EQUILIBRIUM}

A Cournot-Nash game is characterized by mutual strategic reactions of individual market agents. This results is a Nash equilibrium where all strategies of market agents are the best replies (optimal responses) to the same of the other market participants. In MEMM (Mexican Electricity Market Model), we have divided the country into 3 parts: Mexico North, Mexico City (DF)+Central Part, and Mexico South. Altogether 32 energy suppliers, or market agents, are distinguished, corresponding to their natural establishment areas: Baja California, Baja California Sur, Coahuila, Chihuahua, Durango, Nuevo León, Sonora, Tamaulipas, Aguascalientes, Colima, Distrito Federal (DF), Guanajuato, Guerrero, Hidalgo, Jalisco, Estado de México, Michoacán, Morelos, Nayarit, Puebla, Querétaro, San Luis Potosí, Sinaloa, Tlaxcala, Veracruz, Zacatecas, Campeche, Chiapas, Oaxaca, Quintana Roo, Tabasco, Yucatán.

Each individual energy supplier reacts as a market player, which observes a quantity strategy within a noncooperative oligopolistic game and maximizes her individual profit assuming that all other players also apply the gain maximization strategy. There are allowed to submit electricity to their part, as well as to neighboring parts (e.g., Mexico North supplier can trade within her own region and with DF+Central Part; the DF+Central Part agents can trade with both North and South, as well as within his own region, South can trade within her own region and with the Center). Electricity produced by one competitive player affects the sales and trade volumes of other producers. Within the classical Cournot model, each producer assumes that it is only herself who varies her output, not other producers. At last, at the perfect competition market, agents behave as price takers, equalizing market prices to marginal production costs. Also, we include an open trade scenario, where free electricity trade is established between Mexico and USA.

MEMM can be characterized as a game theoretic model for the electricity market assuming perfect information, constant price elasticity within all regions, linear cost functions and a regional electricity production linked by trade flows. Each producer renders her supply only in one region. Apart from input parameters of electricity production, price elasticity of demand, transportation costs and transmission grid capacities are exogenous. The MEMM determines regional electricity prices, marginal electricity production costs, produced and traded electricity per technology per firm. Principal outcomes are the optimal market shares of each electricity producer in terms of the Hirschmann-Herfindal index (HHI) to measure market concentration, regional prices and interregional trade flows. Introduce the involved parameters, variables, and functions as follows:

$F$
$R$
$I$
$l: F \rightarrow R$

$t(l(f), r)$
$c(i)$
$d e_{0}(r)$
$p e_{0}(r)$

- set of firms

- set of regions

- set of technologies

- location mapping such that $l(f)=r$ if and only if firm

$f$ is located mainly at region $r$

- net access for electricity $l(\mathrm{f})$ to regions including taxes

- variable production costs for technology $i$

- reference demand for electricity in region $r$

- reference price for electricity in region $r$ 


$\begin{array}{ll}\sigma(f, r) & \text { - regional price elasticity of electricity demand in } \\ & \text { region } r \text { conjectured by firm } f \\ \operatorname{capaco}\left(r, r^{*}\right) & \text { - interregional net capacity } \\ x \lim (i, f) & \text { - maximal capacity of technology } i \text { in firm } f \\ p e(r) & \text { - demand price for electricity in region } r \\ m c(f) & \text { - marginal costs of electricity production by firm } f \\ \tau(l(f), r) & \text { - shadow price of electricity transportation from } \\ & \text { region } l(f) \text { to region } r \\ v(f, r) & \text { - market share of firm } f \text { in region } r \\ s(f, r) & \text { - supply of firm } f \text { to region } r \\ x(i, f) & \text { - production by firm } f \text { with technology } i \\ n e t x\left(r, r^{*}\right) & \text { - net export of electricity from region } r \text { to region } r^{*}\end{array}$

The Nash equilibrium is determined by the optimality conditions for profit maximization, equalizing marginal production plus transportation costs and prices corrected for monopoly markup and price elasticity of demand. The MCP expression applies the optimality conditions of non-linear programs as KKT conditions and obtains the optimal value of the decision variable due to their upper and lower bounds. Following the Kemfert and Kalashnikov (2002) framework, we can write the equilibrium conditions as follows.

$m c(f)+\tau(l(f), r)+t(l(f), r)=p e(r)\left(1-\frac{v(f, r)}{\sigma(f, r)} \times n a s h\right), \quad \forall r \in R, \forall f \in F$,

with $\tau(l(f), r)=t(l(f), r)=0 \quad$ if $l(f)=r$, which means that the willingness for an electricity supplier to pay extra charge for net access is zero if the network is not exhausted, and we assume also, that within the regions our network connection is well developed, so we do not run into intra regional energy transfer problems. The coefficient $n a s h=0$ for perfect competition, nash $=1$ for Nash-Cournot equilibrium.

Electricity is transported and traded from region $l(f)$ to region $r$ if $l(f) \neq r$. Marginal production costs may increase together with the shadow prices of the capacity constraints. Net access may include taxes (which aren't in our current version of the model).

In the Nash equilibrium, prices are presented by the inverse demand function which includes price elasticity of demand and the market share of firms. The individual demand share is determined by

$$
v(f, r)=\frac{s(f, r)}{\sum_{g \in F} s(g, r)} \quad \forall r \in R, \forall f \in F .
$$

An upper bound of marginal costs is given by

$$
m c(f) \leq c(i) \quad \forall i \in I, \forall f \in F
$$

Note that this inequality constraint is formulated this way because the lower bound of $m c$ is zero.

The total supply is equal to the total production (that is, the market is cleared completely):

$$
\sum_{i \in I} x(i, f)=\sum_{r \in R} s(f, r) \quad \forall f \in F
$$

Aggregate supply of firms in region $r$ equals the corrected total demand in that region, i.e. 


$$
\sum_{f \in F} s(f, r)=d e_{0}(r) \cdot\left(\frac{p e(r)}{p e_{0}(r)}\right)^{-\sigma(r)} \quad \forall r \in R
$$

where $\sigma(r)>0$ is a parameter based upon the elasticity conjectured by firms-producers at region $r$. We assume that the elasticity parameters are 0.4 for North and Central Mexico, which is standard for the electricity markets, and 0.29 for South, where we have underdeveloped inter-regional network capacities.

Net exports of region $r$ to region $r^{*}$ with $r \neq r^{*}$ is established by

$n e t x\left(r, r^{*}\right)=\sum_{f \in M} s\left(f, r^{*}\right)-\sum_{f^{*} \in M^{*}} s\left(f^{*}, r\right) \quad \forall r, r^{*} \in R$ and $r \neq r^{*}$,

where $M=\{f \in F \mid l(f)=r\} \quad$ and $\quad M^{*}=\left\{f^{*} \in F \mid l\left(f^{*}\right)=r^{*}\right\}$.

Exports and imports are limited by net capacity:

$$
\operatorname{netx}\left(r, r^{*}\right) \leq \operatorname{capaco}\left(r, r^{*}\right) \quad \forall r, r^{*} \in R \text { and } r \neq r^{*}
$$

The maximum net production of each individual technology $i$ bounds production or supply of electricity by firm $f$ :

$$
x(i, f) \leq x \lim (i, f) \quad \forall i \in I \text { and } \forall f \in F .
$$

Nonnegative constraints are valid for the variables below:

$$
s(f, r), x(i, f), p e(r), m c(f), \tau(l(f), r), v(f, r) \geq 0 .
$$

These models relationships are programmed in the language GAMS as a MCP solved by the algorithm PATH. An optimal solution is found by maximizing regional profits under all the constraints.

\section{Model's Numerical Results and Conclusions}

Tables 1.1 - 1.2 display the perfect competition and Cournot-Nash equilibrium optimal prices, demands, exports and imports, respectively.

Tables $1.3-1.4$ demonstrate the perfect competition and Cournot-Nash equilibrium optimal prices, demands, exports and imports in case of the open market, respectively, e.g., when the United States exporters are able to sell electricity on domestic Mexican market.

Table1. 1. Regional Model Results: Perfect Competition

\begin{tabular}{|l|c|c|c|c|}
\hline Region & $\begin{array}{c}\text { Prices in } \\
\text { Pesos/KWh }\end{array}$ & $\begin{array}{c}\text { Demand in } \\
\text { TWh/year }\end{array}$ & $\begin{array}{c}\text { Export in } \\
\text { TWh/year }\end{array}$ & $\begin{array}{c}\text { Import in } \\
\text { TWh/year }\end{array}$ \\
\hline Region 1 & 0.450 & 74.051 & 62.906 & 60.286 \\
Region 2 & 0.450 & 126.728 & 133.799 & 57.113 \\
Region 3 & 0.500 & 31.430 & 16.947 & 29.783 \\
\hline
\end{tabular}


Table 1.2. Regional Model Results: Cournot-Nash Equilibrium

\begin{tabular}{|l|c|c|c|c|}
\hline Region & $\begin{array}{c}\text { Prices in } \\
\text { EURO/KWh }\end{array}$ & $\begin{array}{c}\text { Demand in } \\
\text { TWh/year }\end{array}$ & $\begin{array}{c}\text { Export in } \\
\text { TWh/year }\end{array}$ & $\begin{array}{c}\text { Import in } \\
\text { TWh/year }\end{array}$ \\
\hline Region 1 & 0.466 & 72.993 & 60.286 & 51.287 \\
Region 2 & 0.534 & 118.396 & 119.041 & 53.880 \\
Region 3 & 0.096 & 26.087 & 20.596 & 20.792 \\
\hline
\end{tabular}

Table 1.3. Regional Model Results with Open Trade : Perfect Competition

\begin{tabular}{|l|c|c|c|c|}
\hline Region & $\begin{array}{c}\text { Prices in } \\
\text { Pesos/KWh }\end{array}$ & $\begin{array}{c}\text { Demand in } \\
\text { TWh/year }\end{array}$ & $\begin{array}{c}\text { Export in } \\
\text { TWh/year }\end{array}$ & $\begin{array}{c}\text { Import in } \\
\text { TWh/year }\end{array}$ \\
\hline Region 1 & 0.378 & 76.220 & 64.555 & 64.357 \\
Region 2 & 0.423 & 126.98 & 134.044 & 57.640 \\
Region 3 & 0.499 & 31.432 & 16.946 & 29.788 \\
\hline
\end{tabular}

Table 1.4. Regional Model Results with Open Trade: Cournot-Nash Equilibrium

\begin{tabular}{|l|c|c|c|c|}
\hline \multicolumn{1}{|c|}{ Region } & $\begin{array}{c}\text { Prices in } \\
\text { EURO/KWh }\end{array}$ & $\begin{array}{c}\text { Demand in } \\
\text { TWh/year }\end{array}$ & $\begin{array}{c}\text { Export in } \\
\text { TWh/year }\end{array}$ & $\begin{array}{c}\text { Import in } \\
\text { TWh/year }\end{array}$ \\
\hline Region 1 & 0.453 & 78.270 & 64.361 & 54.033 \\
Region 2 & 0.512 & 119.504 & 121.88 & 53.344 \\
Region 3 & 0.096 & 26.23 & 21.0 & 20.792 \\
\hline
\end{tabular}

Presently, the Mexican electricity market can be represented as a monopolistic market structure characterized by highly increased prices. But, if we deliver some degree of freedom to the regional representatives of the CFE (we still can have all the production and network centralized and owned by the state corporation - CFE), like the possibility to offer their electricity to neighboring regions, and some net access, we obtain the oligopolistic market with competition of the participants. Quantitatively, this oligopolistic market structure can be realized as a Cournot-Nash equilibrium game, in which the firms maximize their profits. This model is composed in GAMS as a mixed complementarity problem (MCP) solved by a nonlinear complementarity and equation system solvers.

The test calculations show that switch from the monopoly to the classical Cournot-Nash equilibrium may lead to lower consumer prices combined with higher demand, which means higher level of public wealth (domestic social surplus). It seems to be more efficient to allow the domestic supply authorities to trade with neighboring regions by offering their services to customers. The degree of achieved competition can be noticeably high - the comparison to the perfect competition model shows us that the price difference is very small for the northern Mexico, making more difference to the Center and especially South, though. That can be explained by the underdeveloped network connection between central and southern regions of Mexico.

Also, a possibility of international trade shows positive effect on prices and demand growth, but this effect is not crucial due to underdevelopment of the transportation capacities.

\section{ACKNOWLEDGEMENTS}

The work of the second author was supported by the Russian Humanitarian Research Foundation (RGNF) within the grant RGNF 08-02-00271, by the PAICYT grant CE250-09 (Mexico), and by the SEP-CONACYT grant I0010-2009-01-118057 (Mexico).

\section{AUTHOR INFORMATION}

Vitaly Kalashnikov, PhD in Economics from Humbolt University Berlin, 2009; M.Sc. in Financial Mathematics from University of Kaiserslautern, Germany, 2000; M.Sc. in Mathematics from Moscow State University, Moscow, Russian Federation, 2001. Now he is employed as Researcher at CIMAT, Guanajuato, Gto., Mexico. 
Nataliya Kalashnykova, PhD in Operations Research from Institute of Mathematics, Novosibirsk, Russia, 1989; M.Sc. from Novosibirsk State University, Russia, 1978. Now she works as Professor for the Department of Physics and Mathematics at the University of Nuevo León (UANL), Monterrey, NL, Mexico.

Felipe de Jesús Castillo Pérez, M.Sc. in Business and International Trade from the University of Nuevo León (UANL), Monterrey, Mexico, 2005; B.Sc. in Business Engineering from UANL, Monterrey, Mexico, 2000. Now he is PhD students at the Department of Physics and Mathematics at the University of Nuevo León (UANL), Monterrey, NL, Mexico.

\section{REFERENCES}

1. Borenstein, S., Bushnell, J. (1996). An Empirical Analysis of Market Power in a Deregulated California Electricity Market. University of California Energy Institute, Berkeley, CA (January).

2. Bower, J., Bunn, D. (1999). A model-based comparison of pool and bilateral market mechanisms for electricity trading, London.

3. Bulavsky, V.A., Kalashnikov, V.V. (1998). An alternative model of spatial competition. - In: Martine Labbé, Gilbert Laporte, Katalin Tanczos, Philippe Toint (eds.), Operations Research and Decision Aid Methodologies in Traffic and Transportation Management, NATO ASI Series, Series F: Computer and Systems Science, Vol. 166, Springer-Verlag Berlin-Heidelberg, pp. $302-318$.

4. Bulavsky, V.A., Kalashnikov, V.V. (1999). Fuzzy equilibrium in generalized Cournot and Stackelberg models. - In: Rudolf Felix (ed.), Proceedings of the 4th European Workshop on Fuzzy Decision Making, Optimization, and Analysis, Dortmund, Germany, June 14-15, 1999, pp. 25 - 50.

5. Bulavsky, V.A., Kalashnikov, V.V. (1999). Equilibrium in Generalized Cournot and Stackelberg Models. Discussion Paper No. 99116, published at the CentER (Center for Economic Research), Tilburg University, The Netherlands, November 1999, ISSN 0924-7815, pp. 1 - 28.

6. Day, C., Bunn, D. (1999). Generation asset divestment in the England and Wales electricity market: a computational approach to analyzing market power. London.

7. Ferris, M., Pang, J.-S. (1995). Engineering and Economics Applications of Complementarity Problems, Kluwer Academic Publishers.

8. Kalashnikov, V.V. (1995). Complementarity Problems and Generalized Oligopoly Models, (in Russian, Habilitation Thesis), Central Economics and Mathematics Institute, Moscow, 243 pp.

9. Kalashnikov, V.V., Kalashnikova, N.I. (1996). Solving two-level variational inequality, J. Global Optim. 8 (3), pp. $289-294$.

10. Kemfert, C. (1999). Das Mixed Complementarity Problem (MCP) - Problemstellung und Anwendungen. IER AP - 99-3, Stutgart.

11. Kemfert, Claudia, Vitaly Kalashnikov, P.E. Grohnheit, P. Fristrup, R. Denmark, W. Lise, V. Linderhof, L. Bergmann, Chloé le Coq, R. Oestling, R. Tol, Th. Heinzow, J. Bjørndalen, (2005). “Electricity Market

Liberalisation in Europe (EMELIE). Market Imperfections and its Applications on the European Economic and Environmental Situation", Final Report of the EU Project "EMELIE”, Berlin, January 2005, 168 p.

12. Kemfert, C., Kalashnikov, Vitaly V. (2002). Economic effects of the liberalization of the German electricity market - Simulation results by a game theoretic modelling tool. - In: Ronald C. Clute (ed.), Proceedings of the European Applied Business Research Conference (EABRC'2002), Rothenburg, Germany.

13. Klemperer, P.D., Meyer, M. (1989). Supply function equilibria in oligopoly under uncertainty. Econometrica 57 (6), pp. $1243-1277$.

14. Lise, W., Kemfert, C., and R. S. J. Tol (2003). The German electricity market - Does Liberalisation bring competition? Nota di Lavoro, Milan, Italy.

15. Murphy, F., H. Sherali, A. Soyster (1986). A mathematical programming approach for determining oligopolistic market equilibria. Math. Programming 24, pp. $92-106$.

16. Salant, S.W., G. Shaffer (1999). Unequal treatment of identical agents in Cournot equilibrium. The American Economic Review 89 (3), pp. 585 - 604.

17. Wei, J.-Y., Y. Smeers (1999). Spatial oligopolistic electricity models with Cournot generators and regulated transmission prices. Oper. Res. 47 (1), pp. $102-112$. 


\section{NOTES}

